NASA/TM-2008-215416

\title{
CFD Results for an Axisymmetric Isentropic Relaxed Compression Inlet
}

Stefanie M. Hirt and Kathleen M. Tacina

Glenn Research Center, Cleveland, Ohio

Timothy R. Conners, Jason M. Merret, and Donald C. Howe

Gulfstream Aerospace Corporation, Savannah, Georgia

November 2008 


\section{NASA STI Program . . . in Profile}

Since its founding, NASA has been dedicated to the advancement of aeronautics and space science. The NASA Scientific and Technical Information (STI) program plays a key part in helping NASA maintain this important role.

The NASA STI Program operates under the auspices of the Agency Chief Information Officer. It collects, organizes, provides for archiving, and disseminates NASA's STI. The NASA STI program provides access to the NASA Aeronautics and Space Database and its public interface, the NASA Technical Reports Server, thus providing one of the largest collections of aeronautical and space science STI in the world. Results are published in both non-NASA channels and by NASA in the NASA STI Report Series, which includes the following report types:

- TECHNICAL PUBLICATION. Reports of completed research or a major significant phase of research that present the results of NASA programs and include extensive data or theoretical analysis. Includes compilations of significant scientific and technical data and information deemed to be of continuing reference value. NASA counterpart of peer-reviewed formal professional papers but has less stringent limitations on manuscript length and extent of graphic presentations.

- TECHNICAL MEMORANDUM. Scientific and technical findings that are preliminary or of specialized interest, e.g., quick release reports, working papers, and bibliographies that contain minimal annotation. Does not contain extensive analysis.

- CONTRACTOR REPORT. Scientific and technical findings by NASA-sponsored contractors and grantees.

- CONFERENCE PUBLICATION. Collected papers from scientific and technical conferences, symposia, seminars, or other meetings sponsored or cosponsored by NASA.

- SPECIAL PUBLICATION. Scientific, technical, or historical information from NASA programs, projects, and missions, often concerned with subjects having substantial public interest.

- TECHNICAL TRANSLATION. Englishlanguage translations of foreign scientific and technical material pertinent to NASA's mission.

Specialized services also include creating custom thesauri, building customized databases, organizing and publishing research results.

For more information about the NASA STI program, see the following:

- Access the NASA STI program home page at http://www.sti.nasa.gov

- E-mail your question via the Internet to help@ sti.nasa.gov

- Fax your question to the NASA STI Help Desk at 301-621-0134

- Telephone the NASA STI Help Desk at 301-621-0390

- Write to: NASA Center for AeroSpace Information (CASI) 7115 Standard Drive Hanover, MD 21076-1320 
NASA/TM-2008-215416

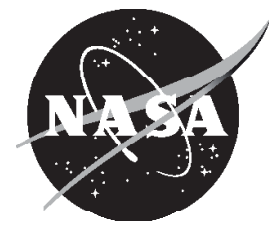

\section{CFD Results for an Axisymmetric Isentropic Relaxed Compression Inlet}

Stefanie M. Hirt and Kathleen M. Tacina

Glenn Research Center, Cleveland, Ohio

Timothy R. Conners, Jason M. Merret, and Donald C. Howe

Gulfstream Aerospace Corporation, Savannah, Georgia

Prepared for the

46th Aerospace Sciences Meeting and Exhibit

sponsored by the American Institute of Aeronautics and Astronautics

Reno, Nevada, January 7-10, 2008

National Aeronautics and

Space Administration

Glenn Research Center

Cleveland, Ohio 44135 
This work was sponsored by the Fundamental Aeronautics Program at the NASA Glenn Research Center.

Level of Review: This material has been technically reviewed by technical management.

Available from

NASA Center for Aerospace Information

7115 Standard Drive

Hanover, MD 21076-1320
National Technical Information Service 5285 Port Royal Road Springfield, VA 22161

Available electronically at $\underline{\mathrm{http}: / / g l t r s . g r c . n a s a . g o v}$ 


\title{
CFD Results for an Axisymmetric Isentropic Relaxed Compression Inlet
}

\author{
Stefanie M. Hirt and Kathleen M. Tacina \\ National Aeronautics and Space Administration \\ Glenn Research Center \\ Cleveland, Ohio 44135 \\ Timothy R. Conners, Jason M. Merret, and Donald C. Howe \\ Gulfstream Aerospace Corporation \\ Savannah, Georgia 31402
}

\begin{abstract}
The OVERFLOW code was used to calculate the flow field for a family of five relaxed compression inlets, which were part of a screening study to determine a configuration most suited to the application of microscale flow control technology as a replacement for bleed. Comparisons are made to experimental data collected for each of the inlets in the 1- by 1-Foot Supersonic Wind Tunnel at the NASA Glenn Research Center (GRC) to help determine the suitability of computational fluid dynamics (CFD) as a tool for future studies of these inlets with flow control devices. Effects on the wind tunnel results of the struts present in a high subsonic flow region accounted for most of the inconsistency between the results. Based on the level of agreement in the present study, it is expected that CFD can be used as a tool to aid in the design of a study of this class of inlets with flow control.
\end{abstract}

\section{Introduction}

A supersonic inlet is used to decelerate and compress the flow before it enters the engine. Due to the compression, an adverse pressure gradient exists in the inlet that causes thick boundary layers to develop. Bleed has become the standard means of reducing the effects of the boundary layer. Part of the low velocity flow in the boundary layer is removed, leaving a higher average flow velocity in the inlet. However, since air is being removed from the system, the inlet must be larger to provide the same total mass flow to the engine, and the bleed flow is dumped overboard, which adds significant drag. Microscale flow control devices (refs. 1 and 2) are another potential means of controlling boundary layer development that are of interest as an alternative to bleed due to their low weight and mechanical simplicity.

A series of five external compressions, axisymmetric inlets were tested at the NASA Glenn Research Center 1- by-1 Foot Supersonic Wind Tunnel (ref. 3). Figure 1 shows a view of one of the inlets in the tunnel. The inlets were part of a screening study to determine a configuration most suited to the application of microscale flow control technology as a replacement for bleed. Each inlet employed forward centerbody surface shaping to relax flow compression in the cowl highlight region. Relative to inlet geometry produced using traditional methods, this novel design technique can significantly reduce cowling angle and, therefore, nacelle drag. By capitalizing on fixed surface geometry redefinition, relaxed compression provides a simpler approach to improving installed propulsion performance compared to methods that focus on maximizing total pressure recovery.

While the novel shaping technique can provide a more mechanically simple approach to improving installed propulsion system performance, there are two primary limitations: tip distortion increases because of the stronger normal shock that results from the relaxed isentropic compression, and boundary layer health is reduced behind the base of the terminal shock because of the increased post-shock flow turning angle required to maintain an acceptable subsonic diffusion profile. Based on the results of this first test, one of the inlets may be adapted to include microramps, which are wedge-shaped vortex 
generators with a height approximately 40 percent of the boundary layer thickness. In the inlets with the most aggressive centerbody turning, the need for flow control is expected to be more critical because boundary layer separation is likely.

Backpressured computational fluid dynamics (CFD) solutions were completed for each of the five inlet configurations. To aid in the design of the flow control array that will be incorporated into a selected inlet, future CFD studies will be conducted to evaluate the effectiveness of a variety of microramp arrays in the inlet. A strong similarity between the CFD and experimental results in the present study would provide added confidence in the use of future CFD studies to simulate the inlet with flow control devices.

This paper will compare CFD results for the pressure recovery versus mass flow ratio curve (i.e. the cane curve) to the same generated experimentally, as well as comparisons of the static pressure profiles along the inlet centerbody and cowl, and AIP Mach number and total pressure recovery profiles for each of the inlet configurations.

\section{CFD Method}

The OVERFLOW code (ref. 4) was used to study the performance of the inlets. OVERFLOW is a Reynolds-averaged Navier-Stokes solver and can be used for turbulent, compressible flows. Turbulence was modeled using the one-equation Spalart-Allmaras (SA) turbulence model. A two-dimensional axisymmetric structured grid with local timestep scaling was used. The overset grid that was used for the calculations consisted of four zones, as shown in figure 2 . The primary zone contained the entire solution region with a total of 210,000 grid points. The additional zones were overset on the primary zone and used to (1) define the cowl surface, (2) provide grid points on which to interpolate the solution at the AIP, and (3) define the contours of a converging-diverging nozzle downstream of the inlet contours used to determine the mass flow through the inlet. The area ratio of the C-D nozzle was varied to apply the various backpressure levels necessary to characterize the inlet performance.

Boundary conditions were applied to match the test conditions with a uniform Mach number at the inflow plane of 1.974 at a total pressure of 29.0 psia. The inlet surfaces were modeled as no slip, adiabatic walls. To adequately capture the viscous effects, $y+$ values along the inlet surfaces were held to less than 1. The outflow boundary at the exit of the C-D nozzle was a zeroth order boundary with all values extrapolated from the flow field. The solution was initialized to freestream conditions and calculation continued until the maximum residual decreased 5 orders of magnitude.

\section{Experimental Data}

The inlets were designed to be tested at Mach 1.97 and all had the same supersonic diffuser geometry, but the subsonic diffuser length and aerodynamic interface plane (AIP) Mach number were varied. The five configurations examined 2 diffuser lengths - designated short and long - and 3 AIP Mach numbers-

designated low, medium and high - as shown in table 1. The inlet length indicated in the table is specified as an $\mathrm{L} / \mathrm{d}$ ratio where $\mathrm{L}$ is the total length of the inlet, and $\mathrm{d}$ is the inlet diameter at the cowl tip, $3.25 \mathrm{in}$. The inlet with a medium AIP Mach number and a long subsonic diffuser was considered the baseline configuration. The contours of the five inlet configurations are shown in figure 3 . The AIP Mach number was varied by changing the area of the AIP as shown in the figure. The static pressure tap locations are also indicated. The model instrumentation included static pressure taps on the cowl and centerbody and total pressure rakes at the AIP. On the inlet centerbody there were 9 steady state pressure taps and 1 dynamic static pressure tap. On the cowl side there were 13 steady state static pressure taps for the long subsonic diffuser configurations, and for the short configurations there were 8. Two 6-probe AIP total pressure rakes and an AIP dynamic total pressure probe were installed in the model. The rakes could be installed in 10 circumferential locations as shown in figure 4 . The total pressure data presented in this paper is taken from the rake station halfway between the struts, rake slot location 6 from the figure, since this is expected to yield the best agreement with the CFD in which the struts were not simulated. The 
mass flow through the inlet was captured and measured by an ASME Nozzle. Previous publications (refs. 5 and 6) provide further details on the experimental setup.

\section{Results}

The mass flow cane curve gives performance information for an inlet. The mass flow ratio is calculated as the ratio of the inlet mass flow to the capture mass flow. The cowl diameter at the location farthest upstream is used to calculate the capture area. The experiment values for total pressure recovery in figure 5 are calculated based only on area-averaged pressures at rake slot location 6 . The CFD calculations locate the shoulder of the cane curve (the point of maximum total pressure recovery) at a total pressure recovery 1.5 to 2.0 counts higher and a mass flow ratio 0.4 to 2.2 percent lower than seen in the experimental data.

For each configuration, the computed and experimental results at the shoulder of the cane curve (maximum total pressure recovery) were compared in more detail. Note that, from figure 5, these computed and experimental results are at slightly different mass flow ratios. For the comparison cases, the static pressure profiles along the inlet centerbody normalized to the freestream static pressure are shown in figure 6 , and the cowl normalized static pressures are shown in figure 7.

The centerbody surface results show that the static pressure profiles match well for the supersonic portion of the inlet. The normal shock position and strength measured in the experimental data are also well matched by the CFD for all inlet configurations. The subsonic diffuser pressures on both the centerbody and cowl sides do not agree as well. The static pressures in the experimental data are lower than indicated by the CFD solutions, an indication that the code is underpredicting the boundary layer thickness. The Low Mach Short inlet shows the largest magnitude of error. This is likely because the flow is separated in the subsonic diffuser, as will be seen again in other comparisons.

Figures 8 and 9 show AIP profiles of the total pressure ratio and Mach number for the maximum total pressure recovery cases respectively. As was seen in the cane curve, the CFD results predict a higher maximum total pressure ratio compared to the experimental results. This effect is most evident on the cowl side of the profiles but is also present in the core flow. Also of interest is the profile for the Low Mach Short inlet. The centerbody pressures indicate flow separation. This is easily observed looking at the Mach number field for this inlet, which is shown compared to the Medium Mach Long inlet in figure 10. In figure 9, the CFD results consistently show a lower core Mach number than was calculated from the experiment, which is expected given the higher predicted static pressure.

Overall the agreement between the CFD and experimental results is good, but there are some discrepancies. Because comparison cases were selected at the maximum total pressure recovery, there was some mismatch in the mass flow, which could account for the variations in AIP Mach number and the static pressure profiles, particularly near the inlet exit. Figure 11 shows results for the Medium Mach Long inlet comparing cases with matching mass flow rates. The agreement in static pressure and AIP Mach number is no better for the matching mass flow cases than for the cases selected at maximum total pressure recovery.

Looking at the trends present in the comparisons, many of the differences are explained by the effects of the struts on the experimental data, which is not simulated in the axisymmetric CFD. While the struts are thin, the high subsonic Mach number in the region of the struts causes the blockage to be meaningful. At the same mass flow ratio, the Mach number through the strut region would increase due to the blockage, accounting for the lower static pressures seen in the experimental data. Losses due to the struts also explain the lower total pressure recoveries measured at the AIP.

\section{Conclusions}

The OVERFLOW code was used to calculate the flow field for a family of five relaxed compression inlets designed to have low boom and drag. The inlets, designed for Mach 1.974, spanned three AIP Mach numbers, $(0.54,0.60$, and 0.65$)$ and two subsonic diffuser lengths $(1.80$ and $2.11 \mathrm{~L} / \mathrm{d})$. The calculations 
were completed to see how well CFD (in particular, the OVERFLOW code) could simulate inlets of this type, and thus help determine its suitability for future studies with flow control devices.

The computational results show that for the level of fidelity with which the problem was modeled (two-dimensional axisymmetric grid) the calculated values agree well with the experimental data. The presence of the struts in the wind tunnel model explains the discrepancies seen in the data.

While the experimental data looking at boundary layer separation in the inlets were inconclusive, the additional near-wall resolution provided by the CFD indicates that separation is present in the Low Mach Short inlet. The aggressive turning resulting in separation in the inlet makes it an ideal candidate for further study with flow control. Based on the level of agreement in the present study, it is expected that CFD can be used as a tool to aid in the design of a study of this class of inlets with flow control.

\section{References}

1. Lin, J.C., "Review of Research on Low-Profile Vortex Generators to Control Boundary-Layer Separation," Progress in Aerospace Sciences 38, pp. 389-420, 2002.

2. Anderson, B.H., Tinapple, J., and Surber, L., "Optimal Control of Shock Wave Turbulent Boundary Layer Interactions Using Micro-Array Actuation,” AIAA-2006-541, 3rd AIAA Flow Control Conference, San Francisco, CA, June, 2006.

3. Seablom, K.D., Soeder, R.H., Stark, D.E., Leone, J.F., and Henry, M.W., "NASA Glenn 1- by 1-Foot Supersonic Wind Tunnel User Manual," NASA/TM-1999-208478, 1999.

4. Overflow, Software Package, v2.0y, NASA Langley Research Center, Hampton, VA, 2004.

5. Conners, T.R., Merret, J.M., Howe, D.C., Tacina, K.M., and Hirt, S.M., "Wind Tunnel Testing of an Axisymmetric Isentropic Relaxed External Compression Inlet at Mach 1.97 Design Speed," AIAA2007-5066, July 2007.

6. Tacina, K.M., Hirt, S.M., Conners, T.R., Merret, J.M., and Howe, D.C., "Dynamic Analysis of Wind Tunnel Data from an Isentropic Relaxed Compression Inlet," AIAA-2007-5073, July 2007.

TABLE 1.-PARAMETERS DEFINING THE FIVE INLET CONFIGURATIONS

\begin{tabular}{|cl|c|c|}
\hline \multicolumn{1}{|c|}{ Inlet model } & AIP Mach number & $\begin{array}{c}\text { Inlet length, } \\
\text { L/d }\end{array}$ \\
\hline (a) & Medium Mach Long & 0.60 & 2.11 \\
\hline (b) & High Mach Long & 0.65 & 2.11 \\
\hline (c) & High Mach Short & 0.65 & 1.80 \\
\hline (d) & Low Mach Long & 0.54 & 2.11 \\
\hline (e) & Low Mach Short & 0.54 & 1.80 \\
\hline
\end{tabular}




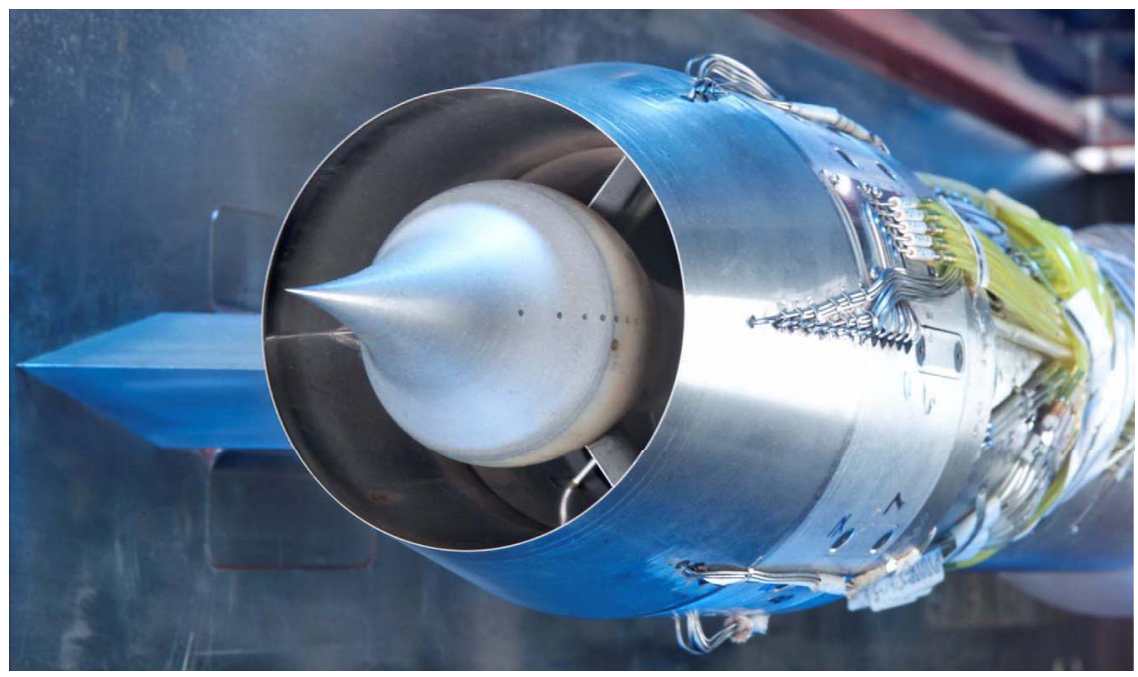

Figure 1.-Photo of the inlet model installed in the wind tunnel.

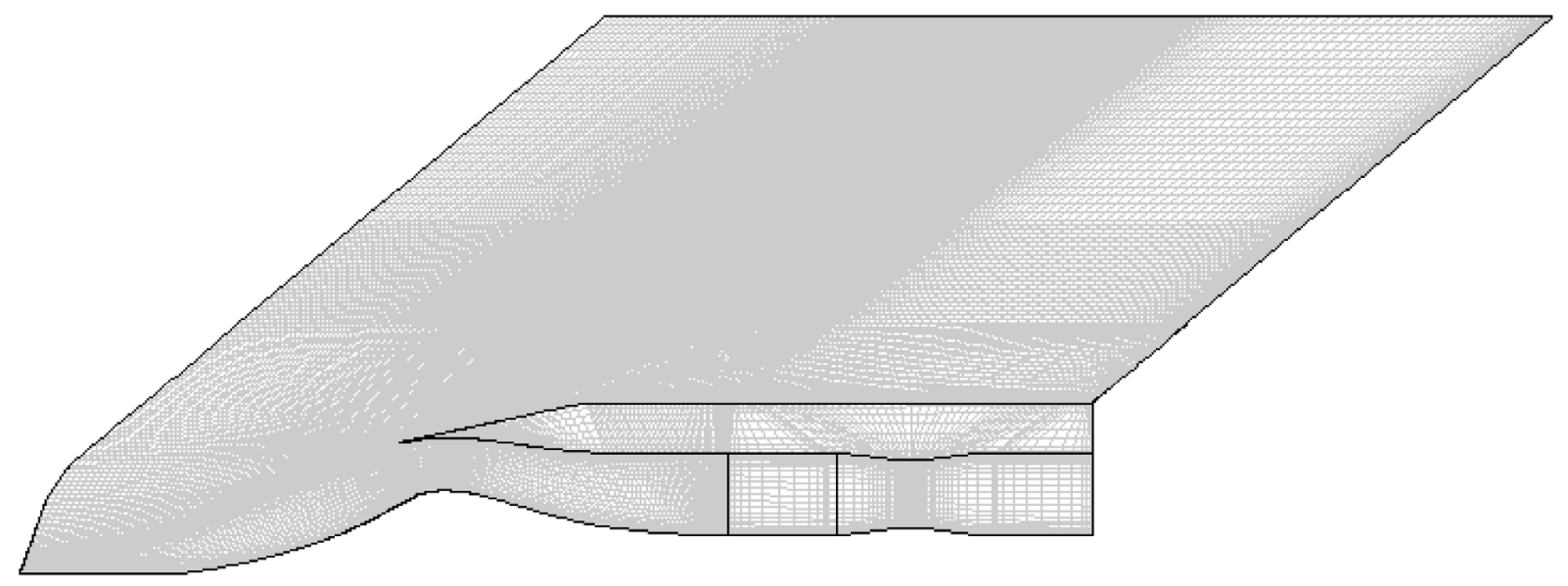

Figure 2.-Grid used for CFD solutions. 

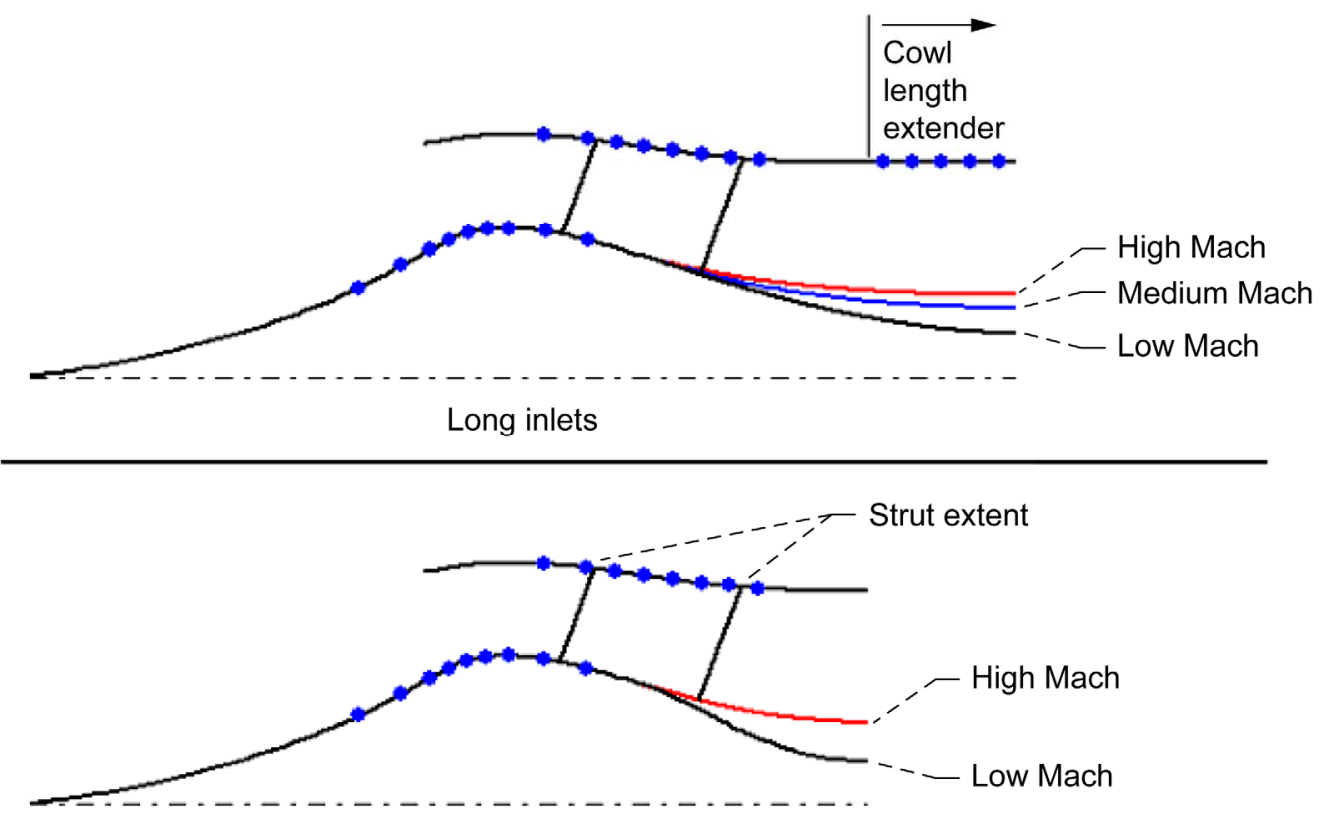

Short inlets

Figure 3.- Inlet contours for the five inlet configurations with the blue dots indicating the locations of the static pressure taps.

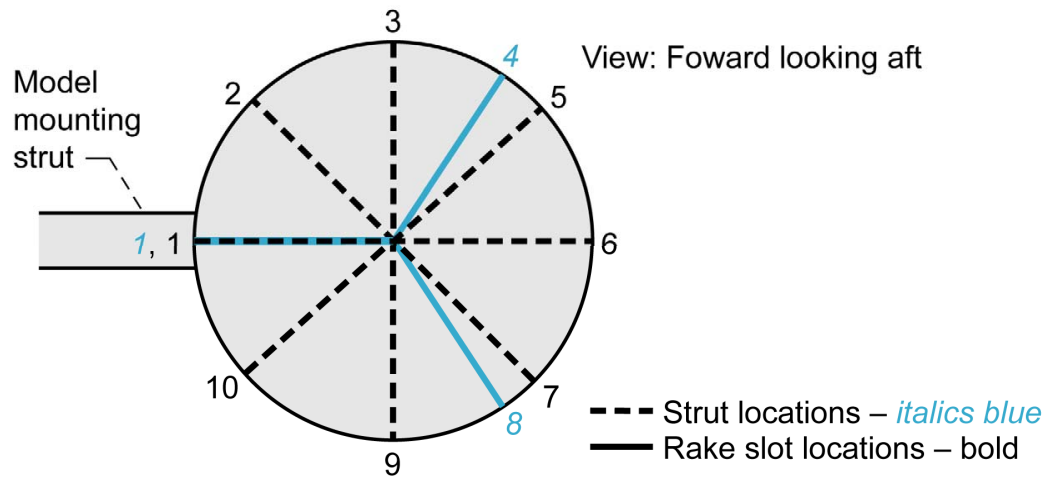

Figure 4.-View of the AIP with the strut locations and possible rake pad positions marked. 

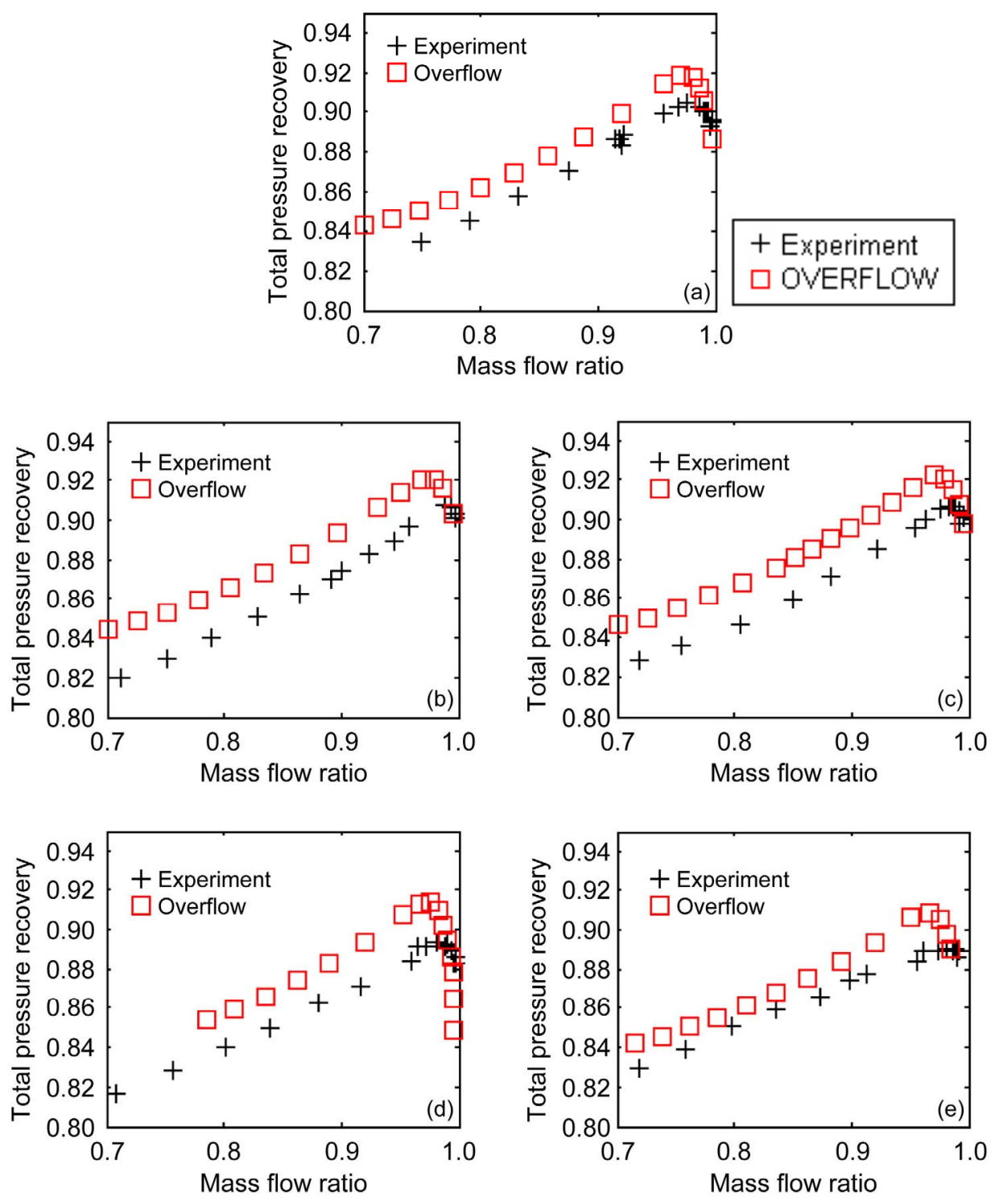

Figure 5.-Cane curve results for the (a) Medium Mach Long (baseline), (b) High Mach Long, (c) High Mach Short, (d) Low Mach Long, and (e) Low Mach Short inlets. 


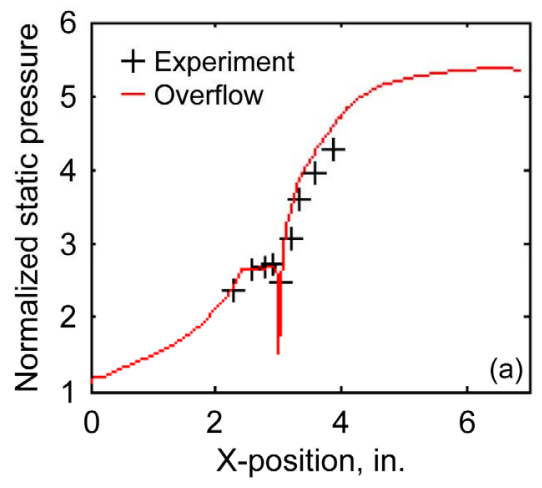

+ Experiment

- OVERFLOW
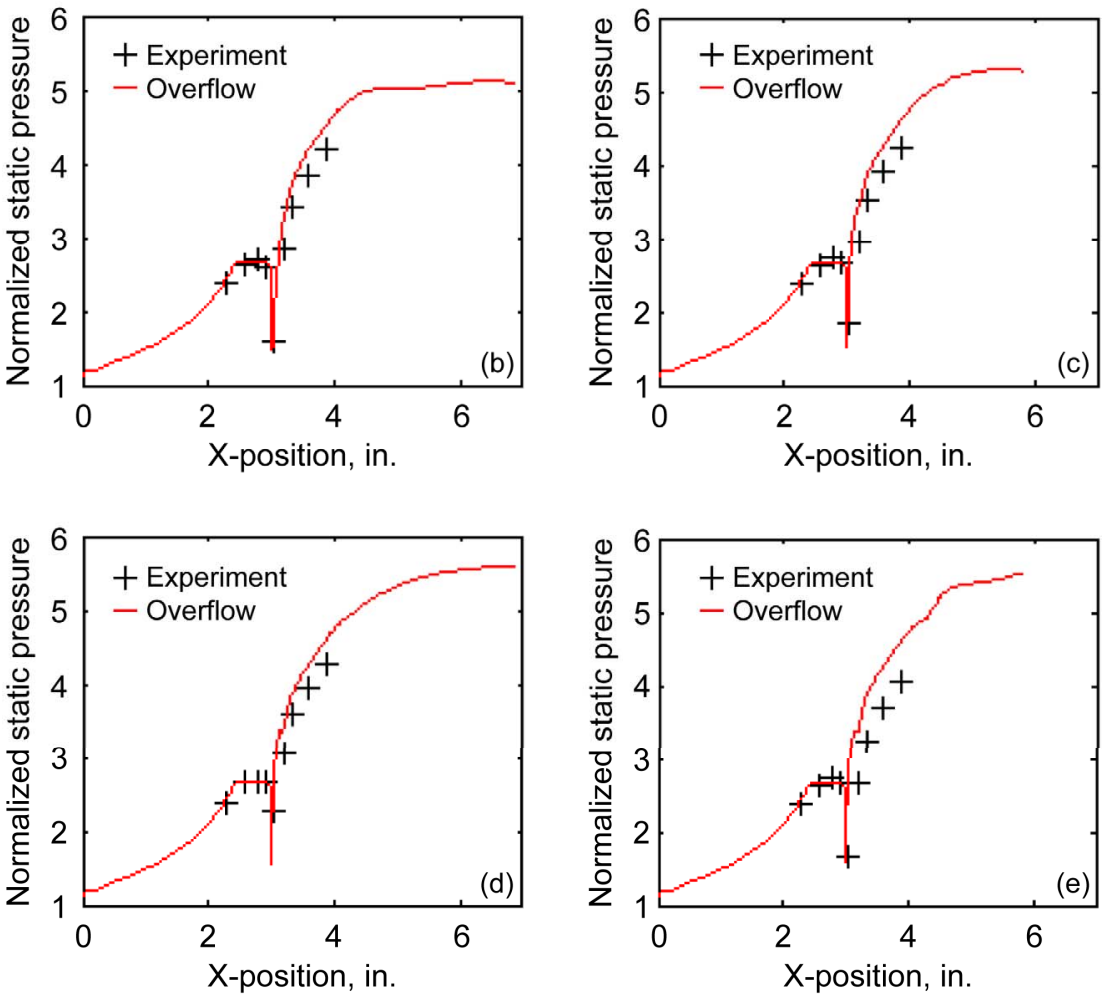

Figure 6.-Centerbody static pressure contours for the (a) Medium Mach Long (baseline), (b) High Mach Long, (c) High Mach Short, (d) Low Mach Long, and (e) Low Mach Short inlets. 


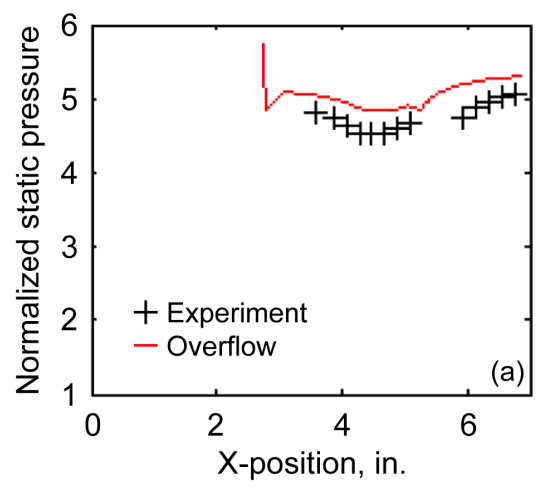

+ Experiment

- OVERFLOW
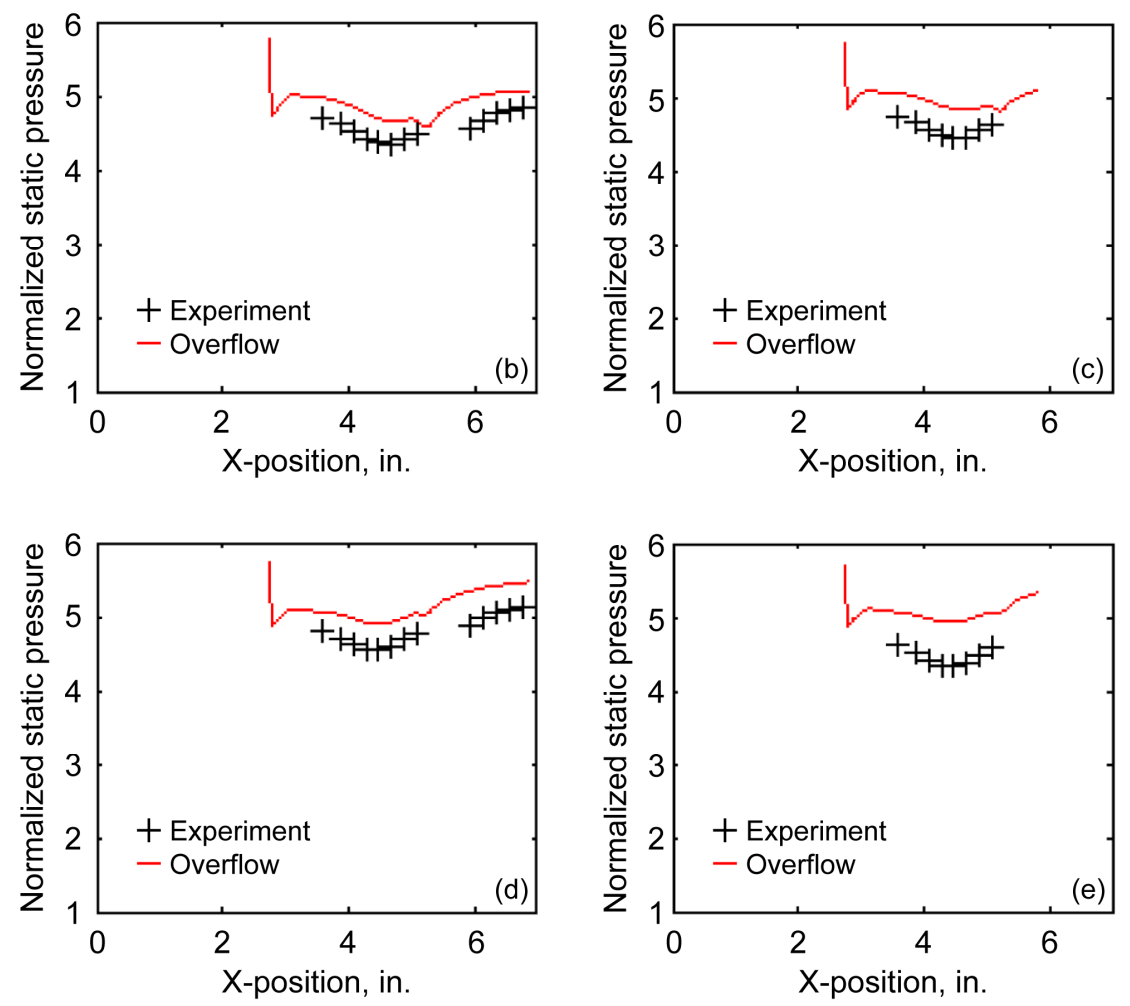

Figure 7.-Cowl static pressure contours for the (a) Medium Mach Long (baseline), (b) High Mach Long, (c) High Mach Short, (d) Low Mach Long, and (e) Low Mach Short inlets. 

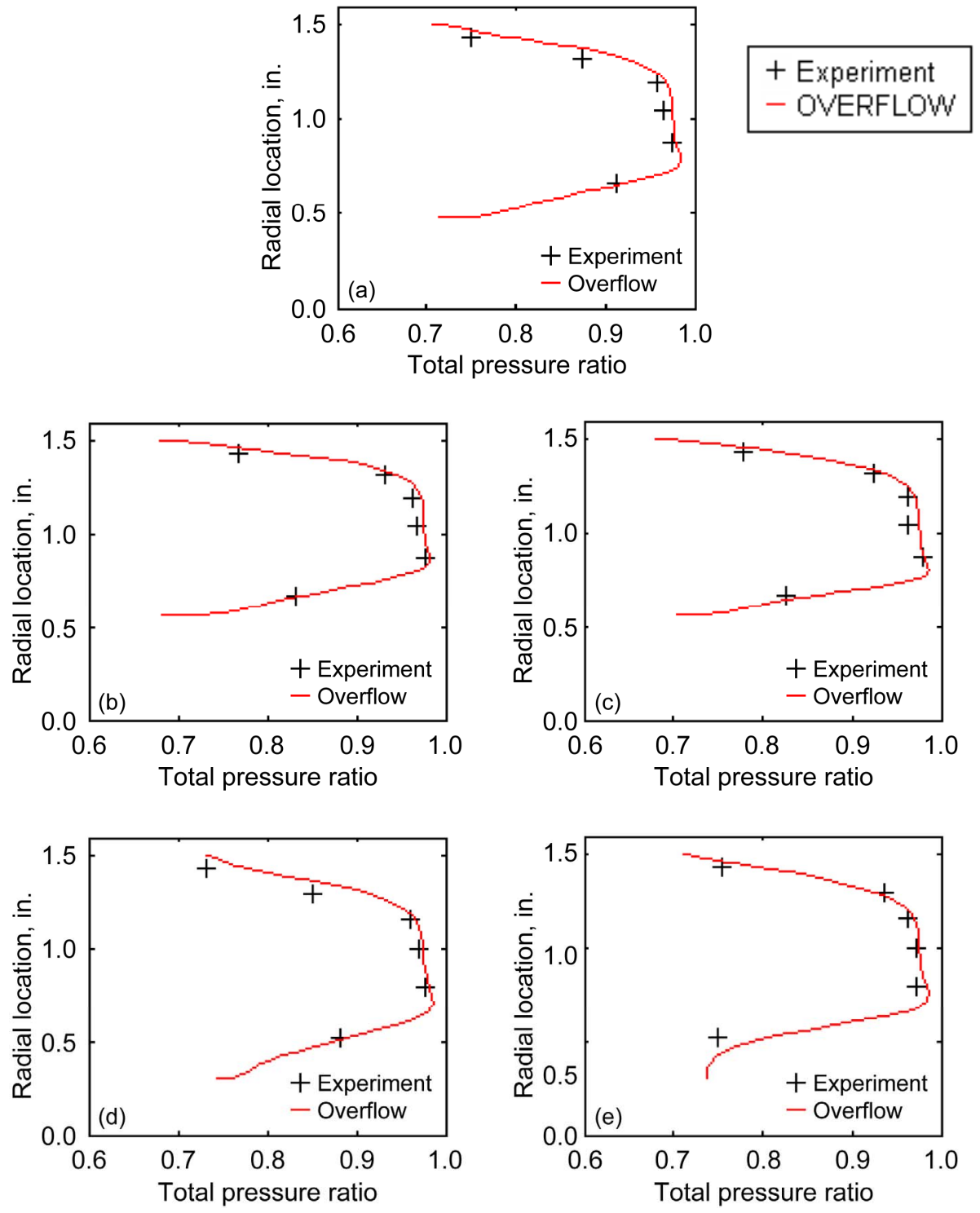

Figure 8.-AIP total pressure ratio profiles for the (a) Medium Mach Long (baseline), (b) High Mach Long, (c) High Mach Short, (d) Low Mach Long, and (e) Low Mach Short inlets. 

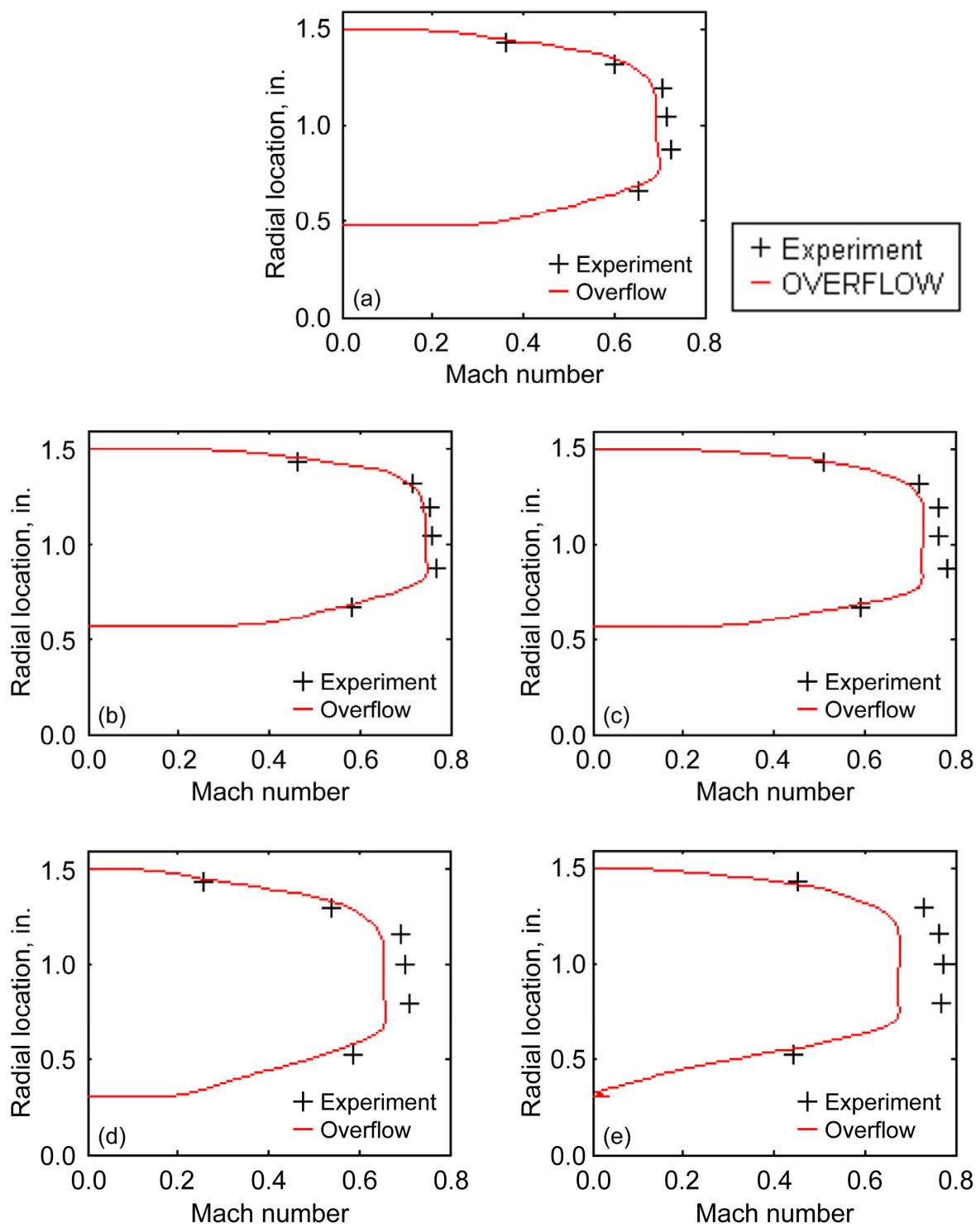

Figure 9.-AIP Mach number profiles for the (a) Medium Mach Long (baseline),

(b) High Mach Long, (c) High Mach Short, (d) Low Mach Long, and (e) Low Mach Short inlets. 

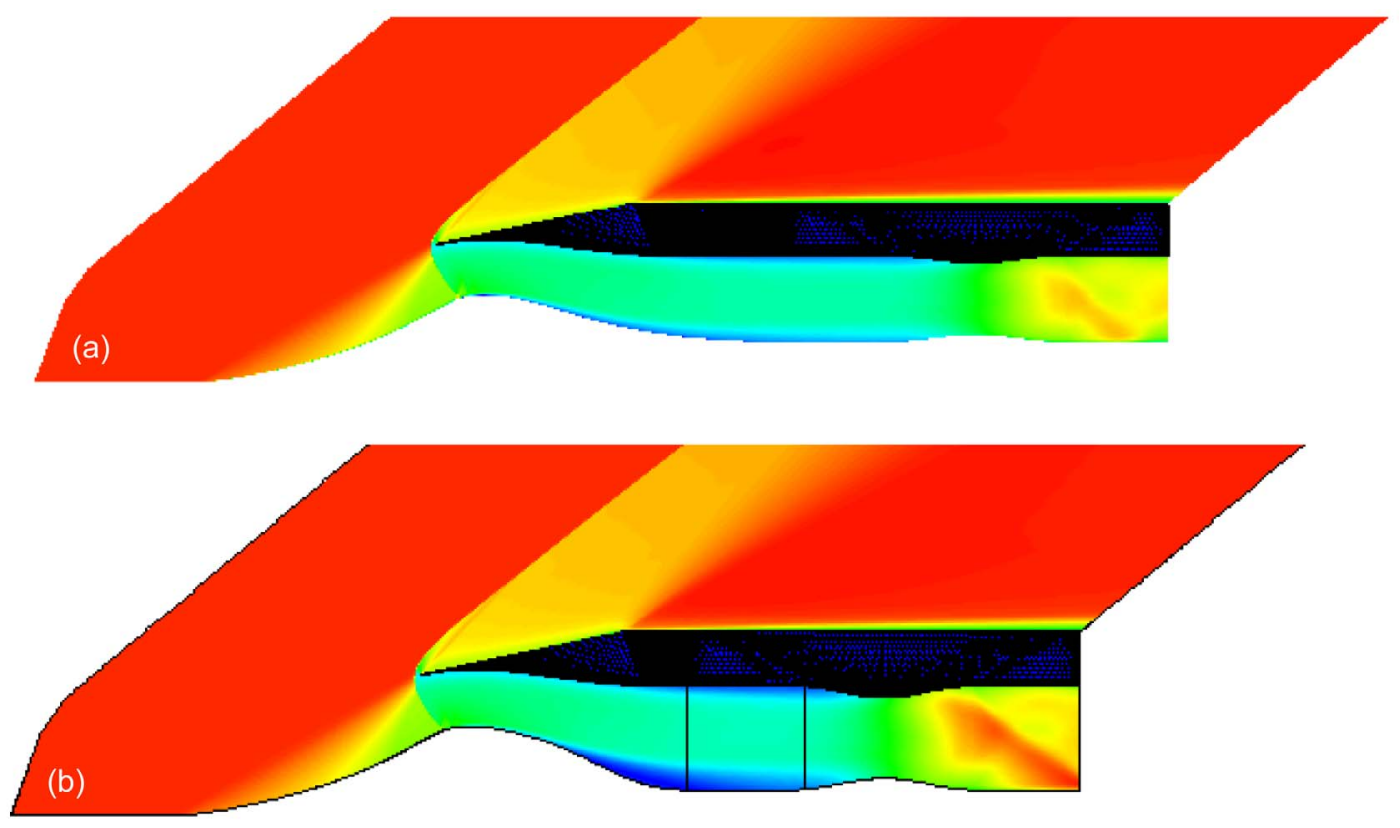

Figure 10.-Mach number solutions in the (a) Medium Mach Long, and (b) Low Mach Short inlets. 

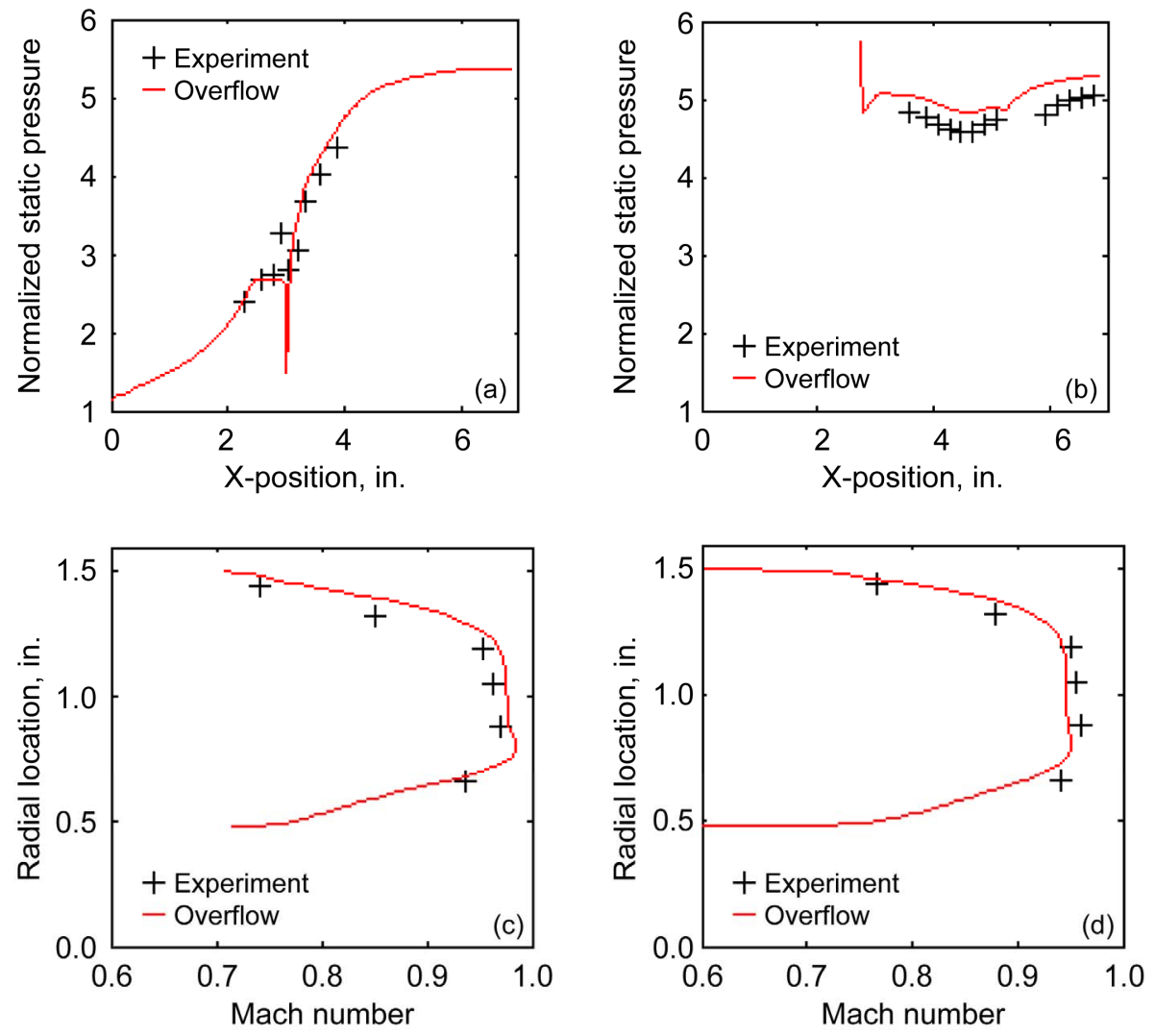

Figure 11.-Comparisons for the Medium Mach Long inlet at matching mass flow conditions of (a) centerbody static pressure profile, (b) cowl static pressure profile, (c) AIP total pressure ratio, and (d) AIP Mach number. 


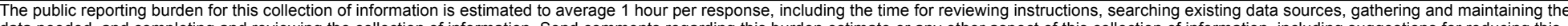

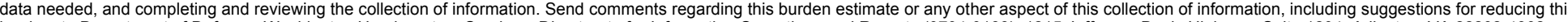

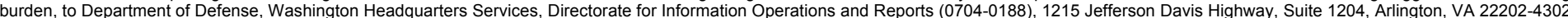

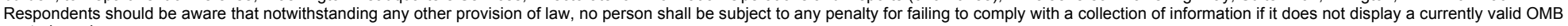
control number.

PLEASE DO NOT RETURN YOUR FORM TO THE ABOVE ADDRESS.

\section{REPORT DATE (DD-MM-YYYY) \\ 2. REPORT TYPE \\ 3. DATES COVERED (From - To)}

01-11-2008

Technical Memorandum

\section{TITLE AND SUBTITLE}

5a. CONTRACT NUMBER

CFD Results for an Axisymmetric Isentropic Relaxed Compression Inlet

5b. GRANT NUMBER

5c. PROGRAM ELEMENT NUMBER

6. AUTHOR(S)

Hirt, Stefanie, M.; Tacina, Kathleen, M.; Conners, Timothy, R.; Merret, Jason, M.; Howe,

Donald, C.

\section{5d. PROJECT NUMBER}

5e. TASK NUMBER

5f. WORK UNIT NUMBER

WBS 984754.02.07.03.13.02

\section{PERFORMING ORGANIZATION NAME(S) AND ADDRESS(ES)}

National Aeronautics and Space Administration

John H. Glenn Research Center at Lewis Field

8. PERFORMING ORGANIZATION

REPORT NUMBER

Cleveland, Ohio 44135-3191

E-16580

\section{SPONSORING/MONITORING AGENCY NAME(S) AND ADDRESS(ES)}

National Aeronautics and Space Administration

Washington, DC 20546-0001

\begin{tabular}{l} 
10. SPONSORING/MONITORS \\
ACRONYM(S) \\
NASA \\
\hline $\begin{array}{l}\text { 11. SPONSORING/MONITORING } \\
\text { REPORT NUMBER } \\
\text { NASA/TM-2008-215416; AIAA-2008- } \\
0092\end{array}$
\end{tabular}

\section{DISTRIBUTION/AVAILABILITY STATEMENT}

Unclassified-Unlimited

Subject Category: 02

Available electronically at http://gltrs.grc.nasa.gov

This publication is available from the NASA Center for AeroSpace Information, 301-621-0390

\section{SUPPLEMENTARY NOTES}

\section{ABSTRACT}

The OVERFLOW code was used to calculate the flow field for a family of five relaxed compression inlets, which were part of a screening study to determine a configuration most suited to the application of microscale flow control technology as a replacement for bleed.

Comparisons are made to experimental data collected for each of the inlets in the 1- by 1-Foot Supersonic Wind Tunnel at the NASA Glenn Research Center (GRC) to help determine the suitability of computational fluid dynamics (CFD) as a tool for future studies of these inlets with flow control devices. Effects on the wind tunnel results of the struts present in a high subsonic flow region accounted for most of the inconsistency between the results. Based on the level of agreement in the present study, it is expected that CFD can be used as a tool to aid in the design of a study of this class of inlets with flow control.

\section{SUBJECT TERMS}

Computational fluid dynamics; Supersonic inlets

16. SECURITY CLASSIFICATION OF:

a. REPORT

$\mathrm{U}$

\section{b. ABSTRACT} $\mathrm{U}$

\section{LIMITATION OF} ABSTRACT

UU

18. NUMBER
OF
PAGES
19

PAGE

$\mathrm{U}$ 19a. NAME OF RESPONSIBLE PERSON

STI Help Desk (email:help@sti.nasa.gov)

19b. TELEPHONE NUMBER (include area code) 301-621-0390 

